\title{
Association between serum resistin concentration and hypertension: A systematic review and meta-analysis
}

\author{
Yuxiang Zhang ${ }^{2,3,4, *}$, Yixing $\mathbf{L i}^{1, *}$, Lin Yu ${ }^{1}$ and Lei Zhou ${ }^{1}$ \\ ${ }^{1}$ State Key Laboratory for Conservation and Utilization of Subtropical Agro-Bioresources, College of Animal Science and \\ Technology, Guangxi University, Nanning, 530004, P.R. China \\ ${ }^{2}$ The Institute for Diabetes, Obesity, and Metabolism, Perelman School of Medicine at the University of Pennsylvania, \\ Philadelphia, PA 19104, USA \\ ${ }^{3}$ Pharmacology Graduate Program, Perelman School of Medicine at the University of Pennsylvania, Philadelphia, PA 19104, USA \\ ${ }^{4}$ Public Health Certificate Program, Perelman School of Medicine at the University of Pennsylvania, Philadelphia, PA 19104, USA \\ *These authors contributed equally to this work
}

Correspondence to: Lei Zhou, email: zhoulei@gxu.edu.cn

Keywords: resistin, hypertension, meta-analysis

Received: March 12, $2017 \quad$ Accepted: April 19, $2017 \quad$ Published: May 02, 2017

Copyright: Zhang et al. This is an open-access article distributed under the terms of the Creative Commons Attribution License 3.0 (CC BY 3.0), which permits unrestricted use, distribution, and reproduction in any medium, provided the original author and source are credited.

\section{ABSTRACT}

Objectives: Recent studies have suggested the involvement of adipokines in the pathogenesis of cardiovascular diseases, including hypertension. In this study, we evaluated the significance of serum resistin levels in hypertensive patients using a meta-analysis approach.

Materials and Methods: Relevant articles were retrieved by searching the following databases: PubMed, Embase, Ovid Medline, ISI Web of Knowledge. The retrieved studies were subjected to a thorough screening procedure to identify case-control studies that contained the required data. Data were extracted from each study and analyzed by Stata software and Review Manager software. In total, 14 case-control studies, containing 718 hypertensive patients and 645 normotensive controls, were included in this study. The major result of the meta-analysis revealed a statistically significant association between serum resistin concentration and hypertension $(\mathrm{SMD}=0.85,95 \% \mathrm{CI}:[0.15,1.54])$, and the association was more obvious in Asian and Hispanic populations, diabetic population and studies with larger size cohorts. Publication bias was a low probability event for overall comparisons.

Conclusions: Based on our results, we conclude that serum resistin level in hypertensive patients is higher than normotensive controls, indicating resistin might be a risk factor for hypertension.

\section{INTRODUCTION}

Resistin is a $12.5 \mathrm{kDa}$ cysteine-rich polypeptide discovered in a screen for adipocyte gene products that are down regulated by anti-diabetic thiazolidinedione (TZD) drugs in mice [1]. In rodents, resistin is an adipokine, secreted from white adipocytes and is reported to regulate glucose metabolism and insulin sensitivity [2]. Systemic treatment or transgenic overexpression of resistin in rodents decreases the ability of insulin to suppress hepatic glucose production $[3,4]$. Conversely, ablation of the retn gene or reduction in resistin protein by antisense oligonucleotide treatment improves insulin sensitivity through AMPK activation $[5,6]$. Resistin is detectable in human serum, but unlike rodent resistin, human resistin is predominantly produced by macrophages [7], and as in rodents, resistin level decreases with thiazolidinedione treatment in humans [8]. Besides a role in metabolism, resistin has also been associated with cardiovascular diseases (CVD) [9-11]. High plasma resistin levels were observed in CVD patients, and its function has been related to vasodilation, and endothelial dysfunction $[9,11]$, indicating that resistin might be involved in the regulation of blood pressure. 
Hypertension is one of the most important risk factors for coronary heart diseases and stroke, and has been associated with obesity and diabetes. Recent studies have shown that adipokines, such as adiponectin, leptin and resistin might involve in the development of hypertension [12, 13]. Many studies have investigated the correlation between circulating resistin levels and hypertension. The results of initial efforts were conflicting, with some, but not all studies identifying a significant correlation between serum resistin level and hypertension incidence. Thomopoulos and colleagues reported that increased resistin and decreased adiponectin plasma levels are asscciated with sustained and masked hypertension, and resistin is associated 2.5 times more frequently with sustained hypertension than with masked hypertension [14]. However, Olszanecka and colleagues did not find any difference in the serum resistin level between the hypertensive and normotensive pre- and post-menopausal women [15]. The discrepancy among study results could be related to differing demographics of the study groups as well as the various sample sizes. Therefore, in this study we carried out a systematic review to synthesize and analyze the published data on the association of resistin with the risk of hypertension.

\section{RESULTS}

\section{Characteristics of enrolled studies}

The database search originally resulted in retrieval of 1995 articles related the search keywords. The flow diagram of the study selection process is presented in Figure 1. Finally, 15 articles were included in the systematic review and 13 articles containing 14 casecontrol studies were enrolled in the meta-analysis [14-26]. The major discovery of the two studies that are excluded from the meta-analysis were summarized in Supplementary Table 2. The publication year of these studies ranged between 2003 and 2013. All articles were case-control studies reporting the relationship between serum resistin levels and hypertension in European, Asian and Hispanic populations. Table 1 displays the basic features of the studies and the detection kits used in each study. The available clinical characteristics of the enrolled studies are summarized in Table 2.

\section{Association between the resistin serum levels and hypertension}

The overall result of the correlation between resistin levels and hypertension is shown in Figure 2. The randomeffect model was applied due to existence of heterogeneity among the studies $(P<0.001)$. A positive association between resistin serum levels and hypertension was identified in this meta-analysis $(\mathrm{SMD}=0.85,95 \% \mathrm{CI}$ : $0.15-1.54$, $P=0.02)$. Subgroup analysis based on the ethnicity revealed that serum resistin levels were significantly higher in hypertensive patients, compared to healthy controls, in both Asian (SMD $=0.48,95 \% \mathrm{CI}: 0.11-0.85, P=0.01)$ and Hispanic populations $(\mathrm{SMD}=1.42,95 \% \mathrm{CI}$ : 0.85-1.99) (Figure 3). The serum resistin trended towards a higher level in European hypertensive patients than the normotensive controls (SMD $=0.93,95 \% \mathrm{CI}:-0.43-2.28, P=0.18$ ) (Figure 3). In addition, resistin level seems to have a stronger correlation with hypertension in diabetic patients, since the subgroup analysis of the diabetic population showed higher standard mean differences in the hypertensive and normotensive population in the diabetic population $(\mathrm{SMD}=1.20,95 \% \mathrm{CI}: 0.32-2.07, P=0.008)$ than the nondiabetic population $(\mathrm{SMD}=0.74,95 \% \mathrm{CI}:-0.14-1.62$, $P=0.10$ ) (Supplementary Figure 1). However, the number of the studies on diabetic population was limited, and thus future studies are needed to confirm this finding. Further, subgroup analysis by sample size indicated that the association between serum resistin level and hypertension were more prominent in the large sample size studies (total study size over 100 , $\mathrm{SMD}=1.87,95 \% \mathrm{CI}: 0.16-3.59, P=0.03)$ than in the small size studies (total study size less than 100, $\mathrm{SMD}=0.40,95 \%$ CI: $-0.10-0.90, P=0.12$ ) (Figure 4).

\section{Sensitivity analysis and publication bias}

The removal of any single study in sensitivity analysis did not change the overall statistical significance, suggesting that this meta-analysis is relatively stable and reliable (Figure 5). Additionally, Egger's test and Begg's test for funnel plot asymmetry showed no significant publication bias among the studies (Figure 6).

\section{Random-effects meta-regression analysis}

In order to look for additional sources of heterogeneity, meta-regression analyses were conducted by incorporating sample size, mean difference of age, difference of gender ratio, and mean difference of body mass index as covariates, while none of them exhibited an obvious confounding influence on the association between the serum resistin levels and hypertension risk (Table 3).

\section{DISCUSSION}

In our analysis, fourteen case-control studies investigating the correlation between serum resistin concentration and hypertension were included. Ten of those studies reported higher resistin level in the hypertension patients, and seven of them were statistically significant. Collectively, our meta-analysis showed that resistin concentration of hypertensive patients was significantly higher than that of normal controls (SMD [95\% CI], $0.85[0.15,1.54])$, indicating that resistin might be a potential risk factor and biomarker for hypertensive patients. 
Resistin in human is mainly produced by the macrophages, and could exert effects on several tissues. To elucidate the mechanisms of resistin regulation in each tissue, several potential resistin receptors have been suggested, including Toll-like Receptor 4 (TLR4) $[27,28]$, an isoform of decorin (DCN), mouse receptor tyrosine kinase-like orphan receptor 1 (ROR1), and adenylyl cyclase-associated protein 1 (CAP1). Since resistin is involved in the regulation of different processes in different cell types and those receptors differ in their tissue distribution, it is possible different receptors could be involved in mediating its numerous effects in various tissues. It has been reported that resistin could regulate metabolic process and adipogenesis in 3T3-L1 cells through its binding to ROR1 and DCN $[29,30]$. On the other hand, resistin could bind to human leucocytes through its interaction with TLR4 and activate pro-inflammatory pathways and cytokine expression [28]. In addition, resistin could also bind to CAP1 in monocytes, whose intracellular signaling pathway could modulate inflammatory action of monocytes [31]. These two receptors might involve in resistin regulation of pro-inflammatory process and its association with cardiovascular diseases [32].

The mechanism underlying the association between the resistin and hypertension still remains to be elucidated. One possible mechanism might be mediated via the TLR4. It has been reported that resistin could induces hypertension in wild type (WT) mice by activating the renin-angiotensin system through up-regulation of $A g t$ expression in the liver [13]. These phenotypes induced by resistin administration were not observed in the $T l \mathrm{r}^{-/-}$ mice, indicating the regulation of blood pressure by resistin is TLR4-dependent. Another potential mechanism is that resistin could reduce endothelial nitric oxide synthase expression, and elevate ET-1 expression as well as its release in human endothelial cells [33, 34]. This could also explain the association between the resistin and hypertension.

In order to consider other factors that may affect the link between serum resistin level and hypertension, we performed a stratified analysis based on ethnicity and sample size. Subgroup analysis showed that the correlation between the resistin and hypertension is more consistently reported in Asian and Hispanic populations. In European hypertensive patients, resistin still trended toward a higher level than the normotensive controls, although the results are more heterogeneous. In addition, the studies with larger cohort size showed more significant correlation between resistin and hypertension patients than the small sized studies. Furthermore, several other potential confounding factors have also been analyzed in this study by the metaregression methods. Still, none of them were correlated with the level of serum resistin, indicating those factors are not likely to explain the differences in the resistin levels between hypertensive patients and normotensive controls.

Several limitations should be acknowledged for the current meta-analysis. First, heterogeneity is a chief

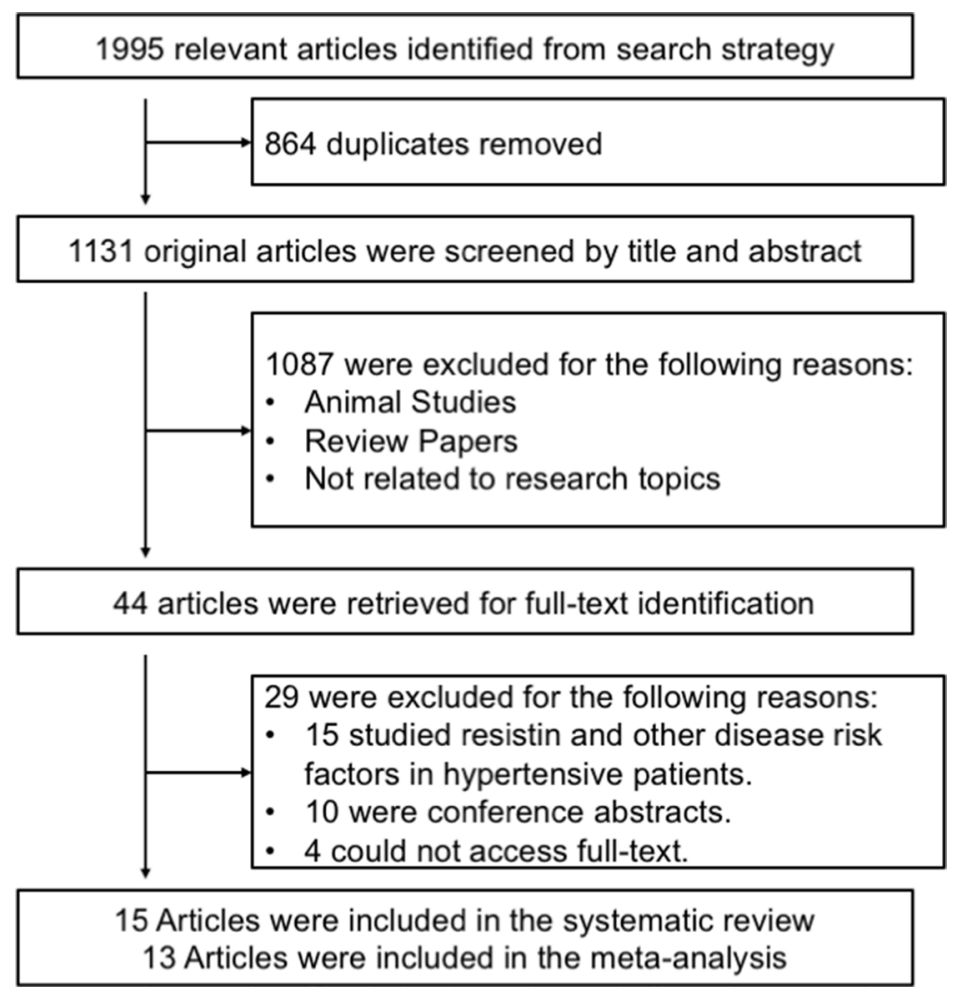

Figure 1: Flow chart of literature search and study selection. 
Table 1: Main features of included studies used in the meta-analysis

\begin{tabular}{|c|c|c|c|c|}
\hline \multirow{2}{*}{ First Author and Year } & \multirow{2}{*}{ Country } & \multicolumn{2}{|c|}{ Study Population } & \multirow{2}{*}{ ELISA Kits } \\
\hline & & Case $(n)$ & Control $(n)$ & \\
\hline Furuhashi M 2003 & Japan & Hypertension Patients (21) & Normotensive Control (18) & Phoenix Pharmaceuticals Inc., Belmont, CA, USA \\
\hline Zhang JL 2003 & China & Hypertensive Type 2 Diabetic Patients (13) & Normotensive Control (12) & Phoenix Pharmaceuticals Inc., Belmont, CA, USA \\
\hline Papadopoulos DP 2005 & Greek & Prehypertension Patients (26) & Normotensive Control (24) & Bio Vendor Laboratory Medicine Inc., Czech Republic \\
\hline Takata Y 2008 & Japan & Hypertensive Type 2 Diabetic Patients (91) & Normotensive Type 2 Diabetic Patients (64) & LINCO Research Inc., St Charles, MS, USA \\
\hline Papadopoulos DP 2009 & Greek & Masked Hypertensive Patients (24) & Normotensive Control (106) & Bio Vendor Laboratory Medicine Inc., Czech Republic \\
\hline Bo S 2009 & Italy & Hypertension Patients (31) & Normotensive Control (27) & R\&D Systems, Minneapolis, MN, USA \\
\hline Yang J 2009 & China & Hypertension Patients (137) & Normotensive Control (134) & Adlitteram Diagnostic laboratories, USA \\
\hline Olszanecka A 2010_1 & Poland & Hypertensive Postmenopausal Women (74) & Normotensive Postmenopausal Women (19) & Bio Vendor Laboratory Medicine Inc., Czech Republic \\
\hline Olszanecka A 2010_2 & Poland & Hypertensive Premenopausal Women (78) & Normotensive Premenopausal Women (21) & Bio Vendor Laboratory Medicine Inc., Czech Republic \\
\hline Thomopoulos C 2011 & Greek & Hypertension Patients (105) & Normotensive Control (130) & Bio Vendor Laboratory Medicine Inc., Czech Republic \\
\hline Mahadik SR 2012 & India & Hypertension Patients (23) & Normotensive Control (41) & LINCO Research Inc., St Charles, MS, USA \\
\hline Stepien M 2012 & Poland & Hypertensive Severe Obesity Patients (10) & Normotensive Simple Obesity Patients (7) & EMD Merck Millipore Corp., Germany \\
\hline Rubio-Guerra AF 2013 & Mexico & Hypertensive Type 2 Diabetic Patients (30) & Normotensive Non-Diabetic Subjects (30) & R\&D Systems, Minneapolis, MN, USA \\
\hline Stepien M 2014 & Poland & Hypertension Patients (55) & Normotensive Patients (12) & DRG Instruments GmbH, Germany \\
\hline
\end{tabular}

Table 2: Clinical measurements available in all the studies included in the meta-analysis

\begin{tabular}{|c|c|c|c|c|c|c|c|c|}
\hline \multirow{2}{*}{ First Author and Year } & \multicolumn{2}{|c|}{ Age (years) } & \multicolumn{2}{|c|}{ Gender $(\mathbf{M} \mid \mathbf{F})$} & \multicolumn{2}{|c|}{ BMI $\left(\mathbf{K g} / \mathbf{m}^{2}\right)$} & \multicolumn{2}{|c|}{ Systolic/Diastolic Blood Pressure (mmHg) } \\
\hline & Case & Control & Case & Control & Case & Control & Case & Control \\
\hline Furuhashi M 2003 & $47.2 \pm 11.7$ & $45.9 \pm 13.7$ & $8 \mid 13$ & $10 \mid 8$ & $24.1 \pm 2.8$ & $24.2 \pm 3.1$ & NA/ NA & NA/NA \\
\hline Zhang JL 2003 & $60.6 \pm 7.2$ & $49.1 \pm 7.5$ & $6 \mid 7$ & $5 \mid 7$ & $29.1 \pm 4.3$ & $22.7 \pm 1.9$ & $159.1 \pm 10.3 / 95.7 \pm 6.2$ & $108.7 \pm 9.2 / 70.6 \pm 8.9$ \\
\hline Papadopoulos DP 2005 & $52 \pm 5$ & $53 \pm 6$ & $14 \mid 12$ & $13 \mid 11$ & $23 \pm 1.5$ & $23.2 \pm 1.4$ & $133 \pm 2 / 87 \pm 2$ & $116 \pm 3 / 76 \pm 2$ \\
\hline Takata Y 2008 & $63.8 \pm 10.4$ & $57.3 \pm 13.9$ & $51 \mid 40$ & $37 \mid 27$ & $25.4 \pm 4.0$ & $25.4 \pm 5.8$ & $140.9 \pm 18.9 / 79 \pm 9.5$ & $120.5 \pm 12.5 / 73.3 \pm 7.0$ \\
\hline Papadopoulos DP 2009 & $46 \pm 7$ & $44 \pm 6$ & $11 \mid 13$ & $52 \mid 54$ & $25.9 \pm 2.1$ & $25.5 \pm 2.4$ & $138 \pm 6 / 90 \pm 4$ & $122 \pm 7 / 79 \pm 4$ \\
\hline Bo S 2009 & $51.1 \pm 5.4$ & $50.8 \pm 4.6$ & NA & NA & 27.9 & $23.9 \pm 3.5$ & $\mathrm{NA} / \mathrm{NA}$ & $\mathrm{NA} / \mathrm{NA}$ \\
\hline Yang J 2009 & $54.1 \pm 8.1$ & $53.0 \pm 7.7$ & $95 \mid 42$ & $68 \mid 66$ & $25.60 \pm 3.19$ & $24.00 \pm 2.73$ & $140.34 \pm 10.47 / 92.69 \pm 7.19$ & $122.37 \pm 11.35 / 79.16 \pm 7.43$ \\
\hline Olszanecka A 2010_1 & $51.9 \pm 2.5$ & $55.6 \pm 3.2$ & $0 \mid 74$ & $0 \mid 19$ & $27.1 \pm 3.3$ & $25.7 \pm 3.5$ & $132.8 \pm 6.3 / 81.8 \pm 8.7$ & $111.9 \pm 7.3 / 70.7 \pm 5.2$ \\
\hline Olszanecka A 2010_2 & $50.1 \pm 2.8$ & $46.3 \pm 2.7$ & $0 \mid 78$ & $0 \mid 21$ & $27.0 \pm 3.1$ & $24.6 \pm 4.7$ & $133.4 \pm 8.1 / 82.5 \pm 6.7$ & $113.8 \pm 5.0 / 71.0 \pm 4.3$ \\
\hline Thomopoulos C 2011 & $47 \pm 6$ & $48 \pm 7$ & $51 \mid 54$ & $74 \mid 56$ & $26.8 \pm 4$ & $26.4 \pm 3.9$ & $146 \pm 4 / 91 \pm 4$ & $126 \pm 5 / 80 \pm 4$ \\
\hline Mahadik SR 2012 & $47.96 \pm 1.45$ & $47.2 \pm 1.31$ & $13 \mid 10$ & $21 \mid 20$ & $22.5 \pm 0.33$ & $22.0 \pm 0.30$ & $136.7 \pm 4.19 / 86.7 \pm 2.91$ & $115.6 \pm 2.45 / 75.8 \pm 1.21$ \\
\hline Stepien M 2012 & $54.30 \pm 12.09$ & $46.57 \pm 13.58$ & $2 \mid 8$ & $3 \mid 4$ & $38.51 \pm 2.96$ & $32.49 \pm 2.18$ & NA/ NA & NA/NA \\
\hline Rubio-Guerra AF 2013 & $60 \pm 9$ & $58 \pm 11$ & $16 \mid 14$ & $19 \mid 11$ & $30.4 \pm 5$ & $29.8 \pm 6$ & $175 / 93$ & $122 / 76$ \\
\hline Stepien M 2014 & $59.3 \pm 7.4$ & $46.5 \pm 12.2$ & $20 \mid 35$ & $5 \mid 7$ & $36.1 \pm 5.5$ & $34.1 \pm 2.60$ & $139.8 \pm 21.2$ & $121.9 \pm 13.9$ \\
\hline
\end{tabular}

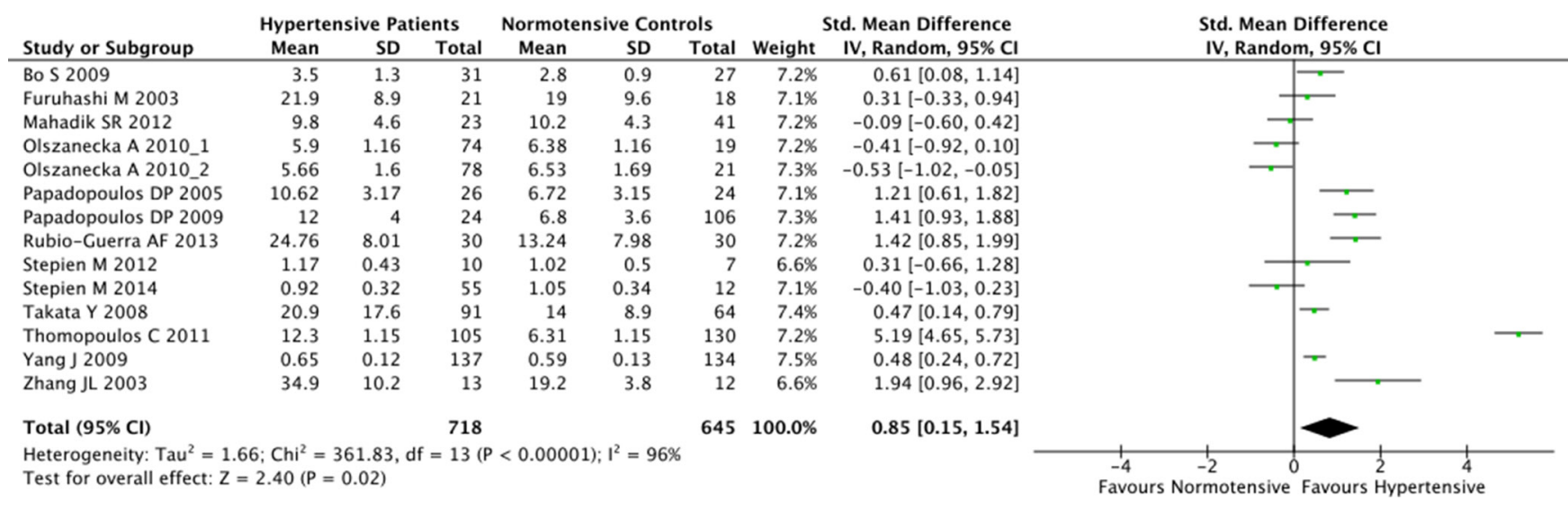

Figure 2: Forest plot of the differences in serum resistin levels between hypertensive patients and healthy controls. Abbreviations: 95\% CI, 95\% confidence interval. 
issue when analyze data from different studies, especially with limited number of studies. Although we have used subgroup and meta-regression analyses to evaluate potential sources of heterogeneity, the heterogeneity from other sources might still interfere with our analyses and conclusions. In addition, in our subgroup analysis of the diabetic and non-diabetic populations, some studies in non-diabetic group did not report clearly whether the patients have defects in glucose metabolism, which could interfere with our interpretation of the result. Second, due to unavailability of the data, only four potential confounding factors were analyzed by meta-regression analyses. Other factors, such as insulin resistance, glucose tolerance, blood glucose level, body fat composition, and

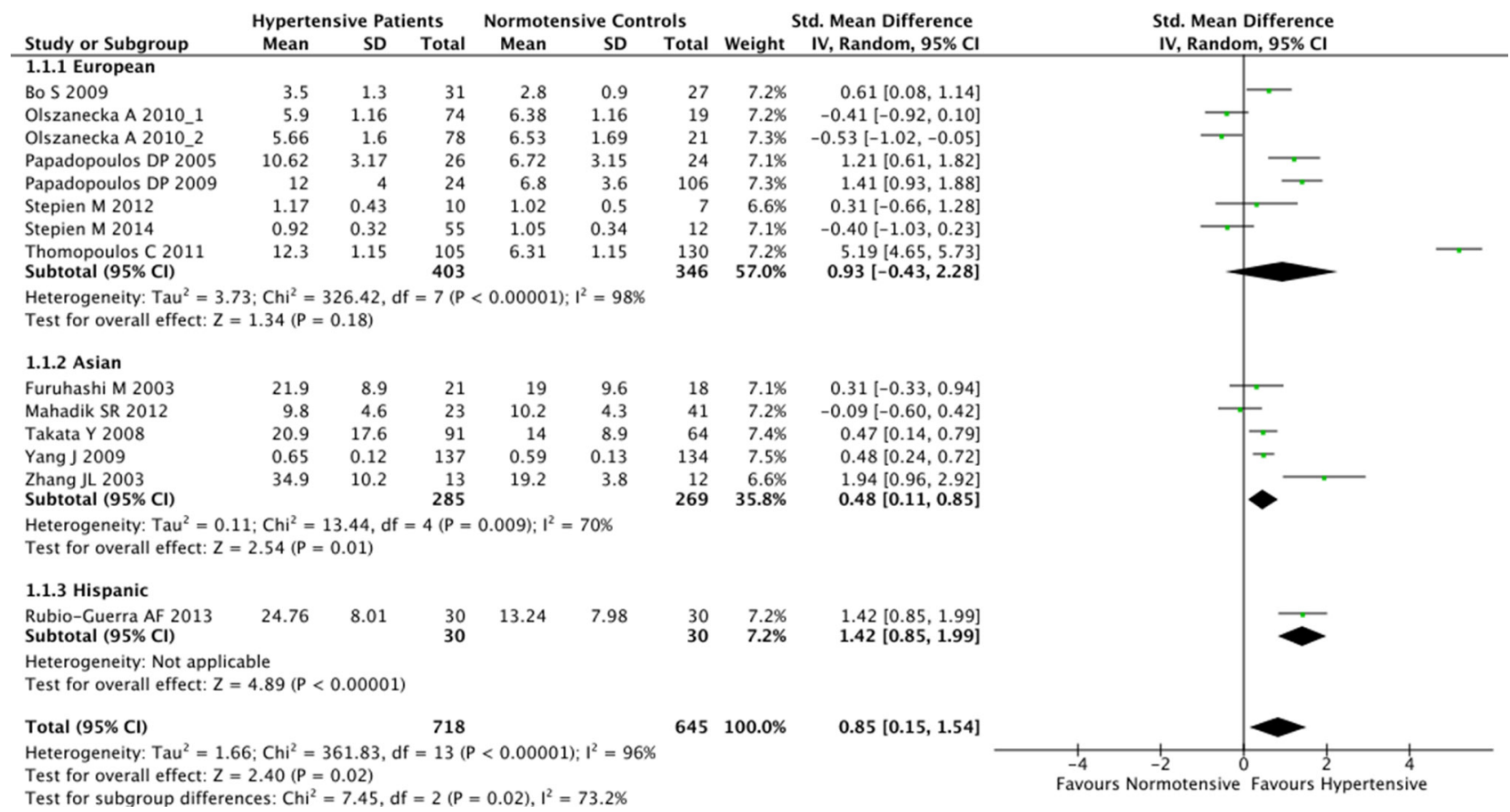

Figure 3: Subgroup analyses for the differences of serum resistin levels between hypertensive patients and healthy controls in different ethnicities. Abbreviations: 95\% CI, 95\% confidence interval.

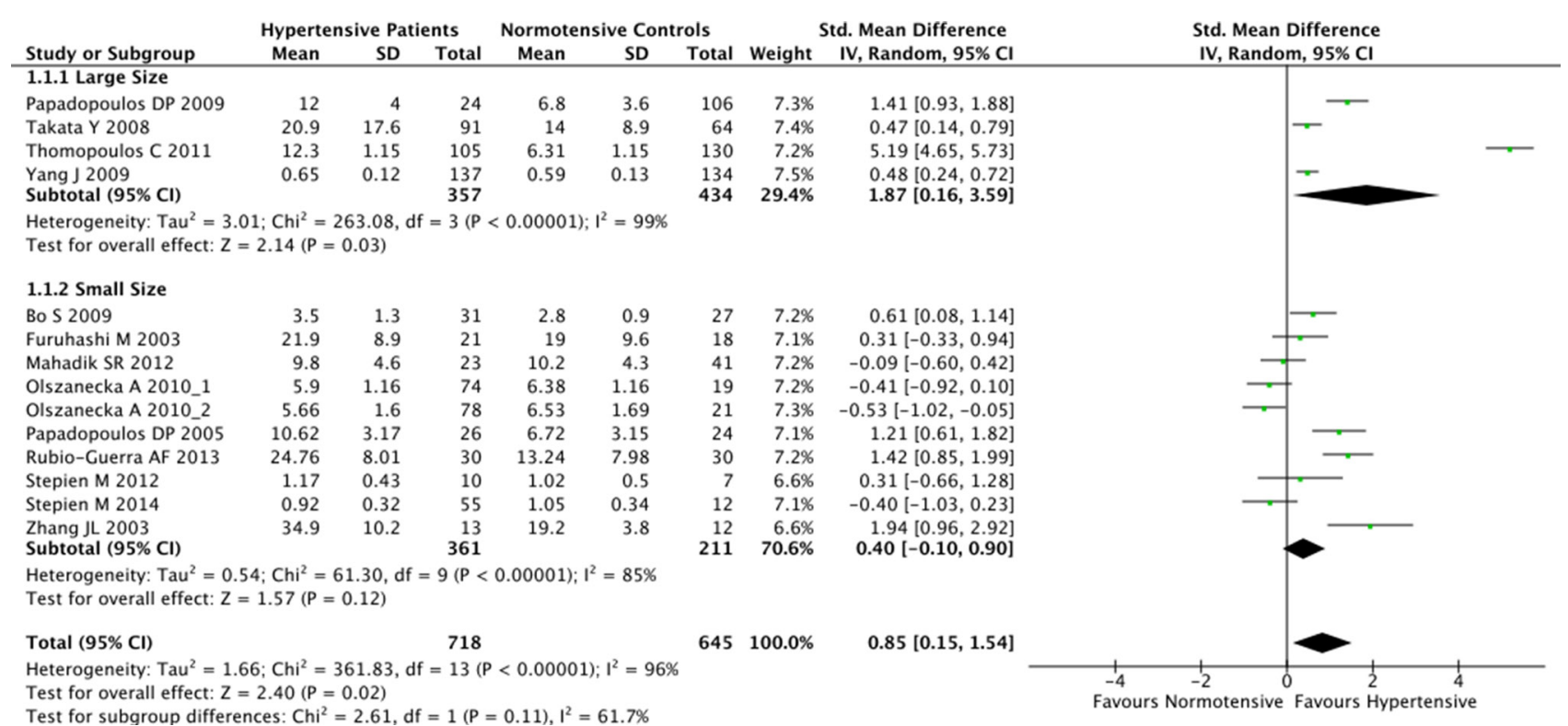

Figure 4: Subgroup analyses for the differences of serum resistin levels between hypertensive patients and healthy controls in studies of different sizes. Studies with total sample size over 100 were considered as large size studies, and studies with a sample size less than 100 were considered as small size studies. Abbreviations: 95\% CI, 95\% confidence interval. 
others, were not analyzed since few studies reported those clinical measurements. Future studies with appropriate controls and more detailed measurement for those factors might be needed to address those issues. Third, our search strategy was limited to the paper published in English and Chinese from the four major publication databases. Articles in other languages and deposited in other databases were not considered, which is susceptible to a literature bias. Last but not least, the studies used in this analysis were all case-control studies, which may prove an association but do not demonstrate causation between the resistin and high blood pressure. It still remains to be shown whether high resistin level contributes to hypertension development, or high blood pressure induces resistin expression in human population by other types of study design.

Taken together, the present study revealed higher serum resistin levels in hypertensive patients compared to healthy controls, indicating that elevated serum resistin levels correlated with hypertension development. Future studies with a larger population and better study design are much needed to confirm this finding, and decide

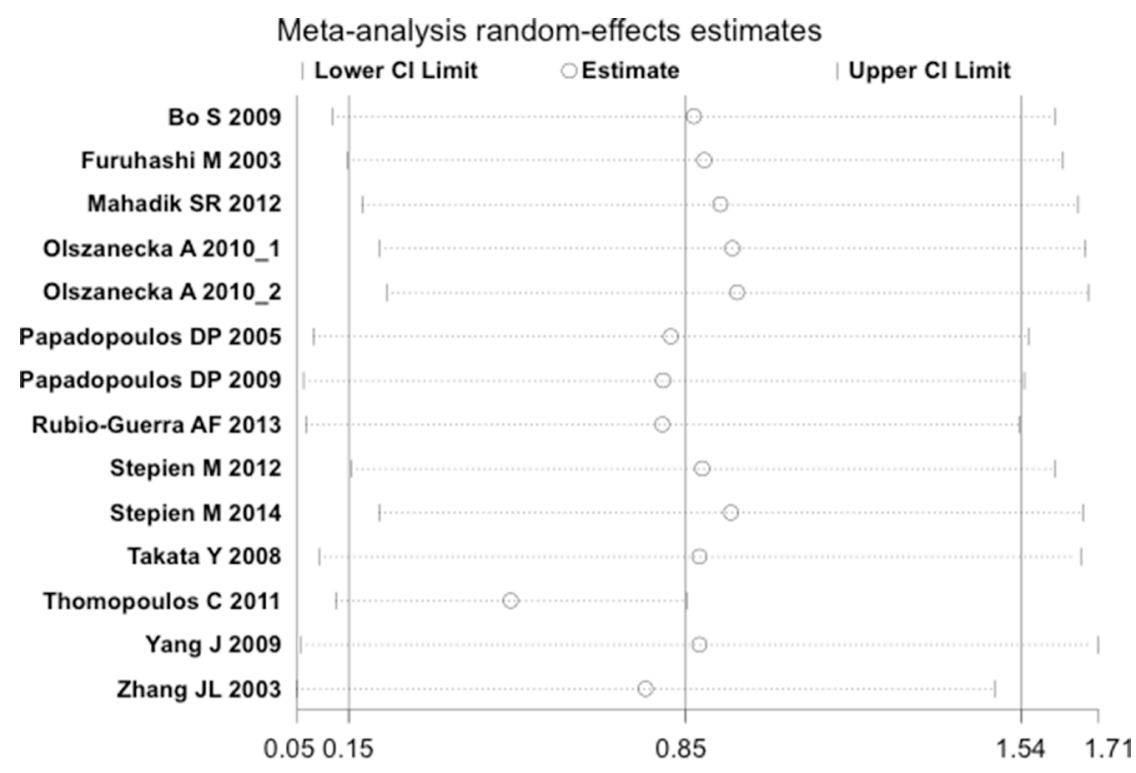

Figure 5: Sensitivity analysis plot of the differences in serum resistin levels between hypertensive patients and healthy controls. Meta-analysis random-effects estimates were used. The two ends of he dotted lines represented the $95 \% \mathrm{CI}$.

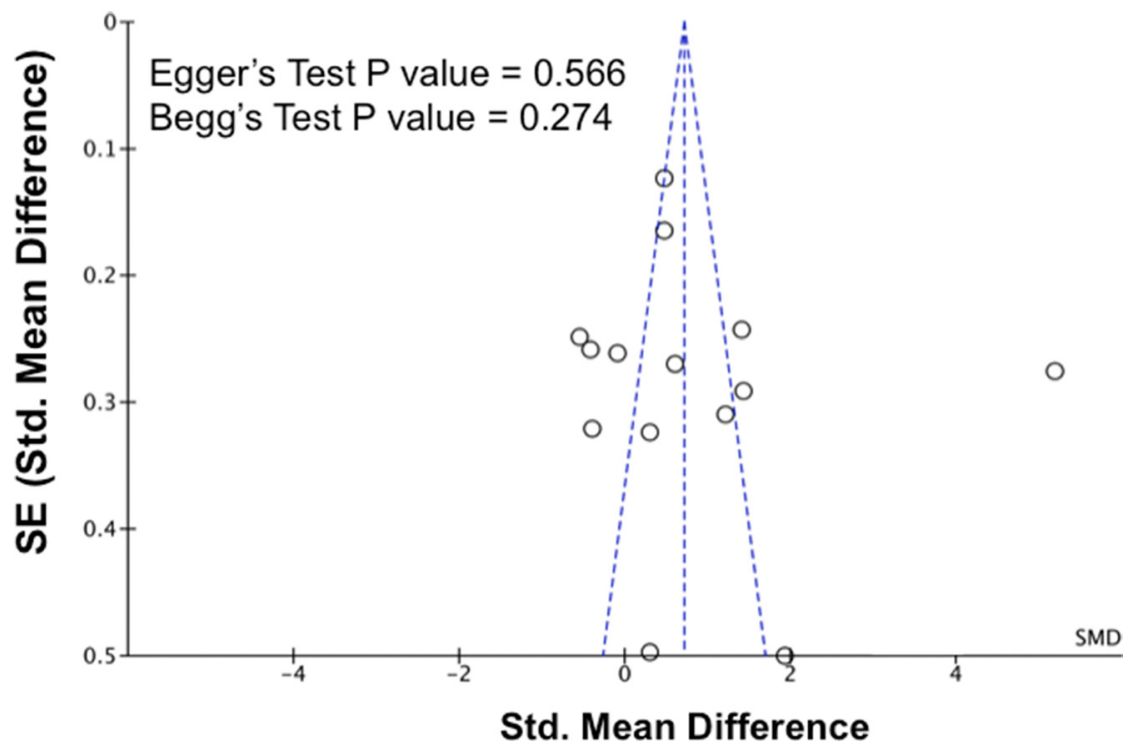

Figure 6: Publication biases on the differences of serum resistin levels between hypertensive and normotensive individuals. The $P$ values for Egger's test and Begg's test are shown in the figure. Abbreviations: 95\% CI, 95\% confidence interval; SE, standard error. 
Table 3: Meta-regression analysis coefficients for serum resistin level in the examined group of studies

\begin{tabular}{lccc}
\hline Variables & Coefficient (SE) & 95\% Confidence Interval & $\boldsymbol{P}$ \\
\hline Sample Size & $0.01(0.01)$ & {$[-0.01,0.02]$} & 0.18 \\
Mean Difference of Age & $-0.05(0.10)$ & {$[-0.27,0.16]$} & 0.59 \\
Difference of Male \% & $-2.13(4.49)$ & {$[-12.01,7.76]$} & 0.65 \\
Mean Difference of BMI & $-0.07(0.21)$ & {$[-0.53,0.38]$} & 0.73 \\
\hline
\end{tabular}

whether resistin may be of clinical value in the treatment of hypertensive patients.

\section{MATERIALS AND METHODS}

\section{PRISMA guideline}

This systematic review and meta-analysis was performed according to the checklist and guidelines from the PRISMA (the preferred reporting items for systematic reviews and meta-analyses) statement [35], as presented in the Supplementary Table 1.

\section{Search strategy}

Published case-control studies were identified via comprehensive search (last search Feb 7th, 2017) of PubMed, Embase, Ovid Medline, ISI Web of Knowledge. The studies reporting the association between serum Resistin levels and hypertension were identified from the databases by utilizing the search terms ("Resistin" or "RETN" or "RELM" or "FIZZ" or "Adipose tissuespecific secretory factor" or "XCP1") and ("hypertension" or "hypertensive" or "blood pressure"). Additionally, manual searches were employed to identify potentially relevant articles from cross-references of important studies.

\section{Study selection}

Randomized case-control studies investigating the association between serum resistin levels and hypertension were considered for this meta-analysis. Duplicate studies or studies lacking complete data were excluded. Only the most complete or the most recent study was enrolled for the duplicate studies.

\section{Data extraction}

To minimize bias and improve the reliability, two investigators independently collected information based on the selection criteria and reached a consensus on all items after discussion and re-examination. The following relevant data were extracted from the eligible studies: surname of first author, year of publication, source of publication, study type, study design, source of publication, sample size, age, gender, ethnicity and country of origin, detection method of serum resistin serum levels, and resistin expression levels. For the studies that only reported median and interquartile range, medians and interquartile ranges were converted to mean and standard deviation according to the method published previously [36]. All authors agreed with the final enrolled studies.

\section{Statistical analysis}

To provide quantitative evidence and minimize variance of the summary, this meta-analysis was performed by applying random-effect model or fixed-effect mode. When heterogeneity existed among studies, a randomeffect model was used; otherwise a fixed-effect model was utilized. We used standard mean difference method to compare the case and control group difference in serum resistin level. Random-effect meta-regression analysis was used to analyze correlation between resistin level and potential confounding factors, including sample size, differences in male percentages, mean difference of age and BMI. Egger's test and Begg's test was used to examine the publication bias in the funnel plots. All statistical analyses were conducted with the usage of STATA software version 14.2 (Stata Corp, College Station, TX, USA) and Review Manager 5.3 (The Cochrane Collaboration).

\section{Abbreviations}

95\% CI: 95\% Confidence Interval; CAP1: CyclaseAssociated Protein 1; CVD, Cardiovascular Diseases; PRISMA: Preferred Reporting Items for Systematic Reviews and Meta-Analyses; ROR1: Receptor Tyrosine Kinase-Like Orphan Receptor 1; SMD: Standard Mean Difference; TLR4, Toll-Like Receptor 4.

\section{Authors' contributions}

Yuxiang Zhang and Lei Zhou conceived the project and design the protocol; Yuxiang Zhang, Yixing Li and Lin Yu performed the experiments; Yuxiang Zhang, Yixing $\mathrm{Li}$ and Lei Zhou wrote the manuscript. All authors read and approved the final manuscript.

\section{ACKNOWLEDGMENTS}

Yuxiang Zhang received supports for his training in epidemiology and public health in the Public Health 
Certificate Program (PHCP) at the University of Pennsylvania.

\section{CONFLICTS OF INTEREST}

The authors have declared that no competing interests exist.

\section{FUNDING}

This work was supported by the grants from National Natural Science Foundation of China (31660641), the Fok Ying Tong Education Foundation (141025), Guangxi Natural Science Foundation (2014GXNSFDA118014), and the Scientific Research Foundation of Guangxi University (XTZ130719).

\section{REFERENCES}

1. Steppan CM, Bailey ST, Bhat S, Brown EJ, Banerjee RR, Wright CM, Patel HR, Ahima RS, Lazar MA. The hormone resistin links obesity to diabetes. Nature. 2001; 409:307-312.

2. Lazar MA. Resistin- and Obesity-associated metabolic diseases. Horm Metab Res. 2007; 39:710-716.

3. Satoh H, Nguyen MT, Miles PD, Imamura T, Usui I, Olefsky JM. Adenovirus-mediated chronic "hyper-resistinemia" leads to in vivo insulin resistance in normal rats. J Clin Invest. 2004; 114:224-231.

4. Rajala MW, Obici S, Scherer PE, Rossetti L. Adiposederived resistin and gut-derived resistin-like molecule-beta selectively impair insulin action on glucose production. J Clin Invest. 2003; 111:225-230.

5. Banerjee RR, Rangwala SM, Shapiro JS, Rich AS, Rhoades B, Qi Y, Wang J, Rajala MW, Pocai A, Scherer PE, Steppan CM, Ahima RS, Obici S, et al. Regulation of fasted blood glucose by resistin. Science. 2004; 303:1195-1198.

6. Muse ED, Obici S, Bhanot S, Monia BP, McKay RA, Rajala MW, Scherer PE, Rossetti L. Role of resistin in dietinduced hepatic insulin resistance. J Clin Invest. 2004; 114:232-239.

7. Patel L, Buckels AC, Kinghorn IJ, Murdock PR, Holbrook JD, Plumpton C, Macphee $\mathrm{CH}$, Smith SA. Resistin is expressed in human macrophages and directly regulated by PPAR gamma activators. Biochem Biophys Res Commun. 2003; 300:472-476.

8. Jung HS, Youn BS, Cho YM, Yu KY, Park HJ, Shin CS, Kim SY, Lee HK, Park KS. The effects of rosiglitazone and metformin on the plasma concentrations of resistin in patients with type 2 diabetes mellitus. Metabolism. 2005; 54:314-320.

9. Ntaios G, Gatselis NK, Makaritsis K, Dalekos GN. Adipokines as mediators of endothelial function and atherosclerosis. Atherosclerosis. 2013; 227:216-221.

10. Burnett MS, Lee CW, Kinnaird TD, Stabile E, Durrani S, Dullum MK, Devaney JM, Fishman C, Stamou S, Canos D,
Zbinden S, Clavijo LC, Jang GJ, et al. The potential role of resistin in atherogenesis. Atherosclerosis. 2005; 182:241-248.

11. Muse ED, Feldman DI, Blaha MJ, Dardari ZA, Blumenthal RS, Budoff MJ, Nasir K, Criqui MH, Cushman M, McClelland RL, Allison MA. The association of resistin with cardiovascular disease in the Multi-Ethnic Study of Atherosclerosis. Atherosclerosis. 2015; 239:101-108.

12. Vlasova M, Purhonen AK, Jarvelin MR, Rodilla E, Pascual J, Herzig KH. Role of adipokines in obesity-associated hypertension. Acta Physiol (Oxf). 2010; 200:107-127.

13. Jiang Y, Lu L, Hu Y, Li Q, An C, Yu X, Shu L, Chen A, Niu C, Zhou L, Yang Z. Resistin Induces Hypertension and Insulin Resistance in Mice via a TLR4-Dependent Pathway. Sci Rep. 2016; 6:22193.

14. Thomopoulos C, Daskalaki M, Papazachou O, Rodolakis N, Bratsas A, Papadopoulos DP, Papavasileiou MV, Perrea D, Makris T. Association of resistin and adiponectin with different clinical blood pressure phenotypes. J Hum Hypertens. 2011; 25:38-46.

15. Olszanecka A, Pośnik-Urbańska A, Kawecka-Jaszcz K, Czarnecka D, Fedak D, Posnik-Urbanska A, KaweckaJaszcz K, Czarnecka D, Fedak D. Adipocytokines and blood pressure, lipids and glucose metabolism in hypertensive perimenopausal women. Kardiol Pol. 2010; 68:753-760.

16. Furuhashi M, Ura N, Higashiura K, Murakami $\mathrm{H}$, Shimamoto K. Circulating resistin levels in essential hypertension. Clin Endocrinol (Oxf). 2003; 59:507-510.

17. Zhang JL, Qin YW, Zheng X, Qiu JL, Zou DJ. Serum resistin level in essential hypertension patients with different glucose tolerance. Diabetic Medicine. 2003; 20:828-831.

18. Papadopoulos DP, Makris TK, Krespi PG, Poulakou M, Stavroulakis G, Hatzizacharias AN, Perrea D, Votteas VV. Adiponectin and resistin plasma levels in healthy individuals with prehypertension. J Clin Hypertens (Greenwich). 2005; 7:729-733.

19. Takata Y, Osawa H, Kurata M, Kurokawa M, Yamauchi J, Ochi M, Nishida W, Okura T, Higaki J, Makino H. Hyperresistinemia is associated with coexistence of hypertension and type 2 diabetes. Hypertension. 2008; 51:534-539.

20. Bo S, Gambino R, Gentile L, Pagano G, Rosato R, Saracco GM, Cassader M, Durazzo M, Cavallo-Perin P. High-normal blood pressure is associated with a cluster of cardiovascular and metabolic risk factors: a populationbased study. J Hypertens. 2009; 27:102-108.

21. Yang J, Li XL, Huang J, Tao F, Li J, Xu Q, Zhang HF, Zhou YL. [Relationship between serum resistin level and large arterial elasticity in patients with essential hypertension]. [Article in Chinese]. Zhonghua Xin Xue Guan Bing Za Zhi. 2009; 37:244-247.

22. Mahadik SR. Association between adipocytokines and insulin resistance in Indian hypertensive patients. Indian Heart J. 2012; 64:35-39.

23. Stẹpień M, Wlazeł RN, Paradowski M, Banach M, Rysz M, Misztal M, Rysz J, Stepien M, Wlazel RN, Paradowski M, 
Banach M, Rysz M, Misztal M, et al. Serum concentrations of adiponectin, leptin, resistin, ghrelin and insulin and their association with obesity indices in obese normo- and hypertensive patients - pilot study. Archives of Medical Science. 2012; 8:431-436.

24. Rubio-Guerra AF, Cabrera-Miranda LJ, Vargas-Robles H, Maceda-Serrano A, Lozano-Nuevo JJ, Escalante-Acosta BA. Correlation between levels of circulating adipokines and adiponectin/resistin index with carotid intimamedia thickness in hypertensive type 2 diabetic patients. Cardiology. 2013; 125:150-153.

25. Stępień M, Stępień A, Banach M, Wlazeł RN, Paradowski M, Rizzo M, Toth PP, Rysz J. New obesity indices and adipokines in normotensive patients and patients with hypertension: comparative pilot analysis. Angiology. 2014; 65:333-342.

26. Papadopoulos DP, Perrea D, Thomopoulos C, Sanidas E, Daskalaki M, Papazachou U, Votteas V, Makris T. Masked hypertension and atherogenesis: the impact on adiponectin and resistin plasma levels. J Clin Hypertens (Greenwich). 2009; 11:61-65.

27. Benomar Y, Gertler A, De Lacy P, Crepin D, Ould Hamouda H, Riffault L, Taouis M. Central resistin overexposure induces insulin resistance through Toll-like receptor 4. Diabetes. 2013; 62:102-114.

28. Tarkowski A, Bjersing J, Shestakov A, Bokarewa MI. Resistin competes with lipopolysaccharide for binding to toll-like receptor 4. J Cell Mol Med. 2010; 14:1419-1431.

29. Daquinag AC, Zhang Y, Amaya-Manzanares F, Simmons PJ, Kolonin MG. An isoform of decorin is a resistin receptor on the surface of adipose progenitor cells. Cell Stem Cell. 2011; 9:74-86.

30. Sanchez-Solana B, Laborda J, Baladron V. Mouse resistin modulates adipogenesis and glucose uptake in 3T3-L1 preadipocytes through the ROR1 receptor. Mol Endocrinol. 2012; 26:110-127.

31. Lee S, Lee HC, Kwon YW, Lee SE, Cho Y, Kim J, Lee S, Kim JY, Lee J, Yang HM, Mook-Jung I, Nam KY, Chung J, et al. Adenylyl cyclase-associated protein 1 is a receptor for human resistin and mediates inflammatory actions of human monocytes. Cell Metab. 2014; 19:484-497.

32. Jamaluddin MS, Weakley SM, Yao Q, Chen C. Resistin: functional roles and therapeutic considerations for cardiovascular disease. Br J Pharmacol. 2012; 165:622-632.

33. Chen C, Jiang J, Lu JM, Chai H, Wang X, Lin PH, Yao Q. Resistin decreases expression of endothelial nitric oxide synthase through oxidative stress in human coronary artery endothelial cells. Am J Physiol Heart Circ Physiol. 2010; 299:H193-201.

34. Verma S, Li SH, Wang CH, Fedak PW, Li RK, Weisel RD, Mickle DA. Resistin promotes endothelial cell activation: further evidence of adipokine-endothelial interaction. Circulation. 2003; 108:736-740.

35. Moher D, Liberati A, Tetzlaff J, Altman DG, Group P. Preferred reporting items for systematic reviews and metaanalyses: the PRISMA statement. BMJ. 2009; 339:b2535.

36. Wan X, Wang W, Liu J, Tong T. Estimating the sample mean and standard deviation from the sample size, median, range and/or interquartile range. BMC Med Res Methodol. 2014; $14: 135$. 